\title{
Students' Learning Obstacles and Alternative Solution in Counting Rules Learning Levels Senior High School
}

\author{
M A Jatmiko ${ }^{1}$ and T Herman ${ }^{2}$, J A Dahlan ${ }^{2}$ \\ ${ }^{1}$ Department of Mathematics Education, Postgraduate School, Universitas Pendidikan Indonesia \\ Jl. Dr.Setiabudhi No. 229, Bandung 40154, Indonesia \\ ${ }^{2}$ Department of Mathematics Education, Universitas Pendidikan Indonesia \\ Jl. Dr.Setiabudhi No. 229, Bandung 40154, Indonesia \\ Email: anangjatmikooo@student.upi.edu
}

\begin{abstract}
The counting rules is a topic in mathematics senior high school. In the learning process, teachers often find students who have difficulties in learning this topic. Knowing the characteristics of students' learning difficulties and analyzing the causes is important for the teacher, as an effort in trying to reflect the learning process and as a reference in constructing alternative learning solutions which appropriate to anticipate students' learning obstacles. This study uses qualitative methods and involves 70 students of class XII as research subjects. The data collection techniques used in this study is diagnostic test instrument about learning difficulties in counting rules, observation, and interview. The data used to know the learning difficulties experienced by students, the causes of learning difficulties, and to develop alternative learning solutions. From the results of data analysis, the results of diagnostic tests researcher found some obstacles faced by students, such as students get confused in describing the definition, students difficulties in understanding the procedure of solving multiplication rules. Based on those problems, researcher analyzed the causes of these difficulties and make hypothetical learning trajectory as an alternative solution in counting rules learning.
\end{abstract}

\section{Introduction}

The advancement of science and technology has colored the world of education today and is a major part of the content of teaching. Education is a very important aspect in supporting the progress of the nation in the future. Through education, humans as the subject of development can be educated, nurtured and developed its potentials. For that in supporting the progress of education, the government also gave great attention to the implementation of education programs in Indonesia. It is proven that the implementation of education in Indonesia has been regulated in the preamble of the 1945 Constitution of the Republic of Indonesia (UUD 1945), namely the Indonesian government participates in the intellectual life of the nation.

In harmony with the educational goals set forth in Law no. 20 Year 2003 Article 3, [1] which formulated that national education functioned to develop the ability and form the character and civilization of dignified nation in order to educate the life of the nation, aims to develop the potential of learners to become human beings who believe, pious to God Almighty, Be noble, healthy, knowledgeable, capable, creative, independent, and become a democratic and responsible citizen. Achieving these 
educational objectives poses challenges including improving the quality, relevance and effectiveness of education as national demands are in line with the development and progress of society, significantly implicated in educational programs and school curricula.

Redja Mudyahardjo stated that education is the teaching that is held in schools as formal educational institutions [2]. Teachers and students are two important aspects of the education process in school. Both are synergized with each other, the teacher can't dominate during the learning process and vice versa. Mathematics learning activities is very important to note, because through good learning activities of mathematics can produce good mathematics skills also for learners. Speaking of mathematical skills, through the Trends in International Mathematics and Science Study (TIMSS) in 2015 conducted a survey of students' math skills in Indonesia. Based on the survey Indonesia obtained a score of 397, ranked 45th out of 50 countries [3]. The 2011 TIMSS Indonesia earned a score of 386 from an average score of 500, ranked 40th out of 45 countries. Judging from the basic competencies developed based on competency standards, can be obtained percentage comparison between the aspects of Numbers, Algebra, Geometry and Measurement, Statistics and Opportunities by 15\%, 37\%, 41\%, 7\% [4]. This indicates that the lack of ability of Indonesian students in solving mathematical problems in the material opportunities in which there are sub-material rules of counting.

The ability to think mathematically can be categorized into low-order thinking to high-level thinking. Working out simple calculations and applying formulas directly is classified into low-level mathematical thinking. While meaningful understanding, composing conjectures, attracting analogies and generalizations, logical reasoning, problem solving, communication and mathematical connections are classed as highlevel mathematical thinking. One of the high-level thinking skills that math subjects aim at at school is the understanding of mathematical concepts, this is contained in the school mathematics curriculum of 2013.

Mathematics learning is a process of learning experiences to students through planned activities, so that students are able to achieve the competence of math materials learned. Suryadi said that basically the learning of mathematics relates to Master, Student, and Mathematics Material [5]. Mathematics learning aims to prepare students to learn mathematics as a mindset in everyday life and mathematics as a science. This task is certainly on the shoulders of a teacher who delivered math materials to students. Math learning in general students are required to not only be able to understand a mathematical concept, but also must be able to use the mathematics to solve problems that are more complicated and require high-level skills such as problem solving.

Referring to the standards of competence and basic competencies that students must achieve, the scope of mathematical material is algebra, measurement and geometry, opportunities and statistics, trigonometry, and calculus. One of the materials in learning mathematics that is studied is the opportunity material. Opportunities can be interpreted as likely to occur from an experiment. Theory of opportunity is very much useful in everyday life, for example in the field of business, meteorology, science, and industry. 
In the life insurance business, life insurance companies use the opportunity to estimate how long a person may live; In the field of medicine, doctors use the opportunity to predict the success of a treatment; In the meteorological field, meteorologists use the opportunity to forecast weather conditions; In the field of science, opportunities are used in the study of the behavior of molecules in a gas and genetic sciences, opportunities are also used to predict the results before election day. In addition, in mathematics learning, opportunity material is the basic science to learn other mathematical concepts such as statistics and combinatory.

Before students learn the material opportunities, there is a prerequisite material that must be mastered is the counting rules. The counting rule consists of several submaterials studied, such as multiplication rules, permutations, and combinations. Some students find it difficult to learn the material of counting rules. The student's mistake in answering the question about the counting rule is shown in the preliminary study results conducted at the school, after the opportunity material is given. Students have not been able to utilize the learning of the opportunity material especially on the sub-material of counting rules (rules of multiplication, permutation, and combination). Students only know and have studied the material of counting rules, but do not understand and able to use them in solving mathematical problems related to the material. Even this material is still considered material that is difficult to learn for students. The difficulties faced by students will certainly be a "stumbling block" for students in learning the material opportunities in full. The result of the analysis of learning obstacles identification test by the researcher can be shown that some students have difficulties in understanding the material of the counting rules. This is seen in the sample student responses as shown by the following figure.

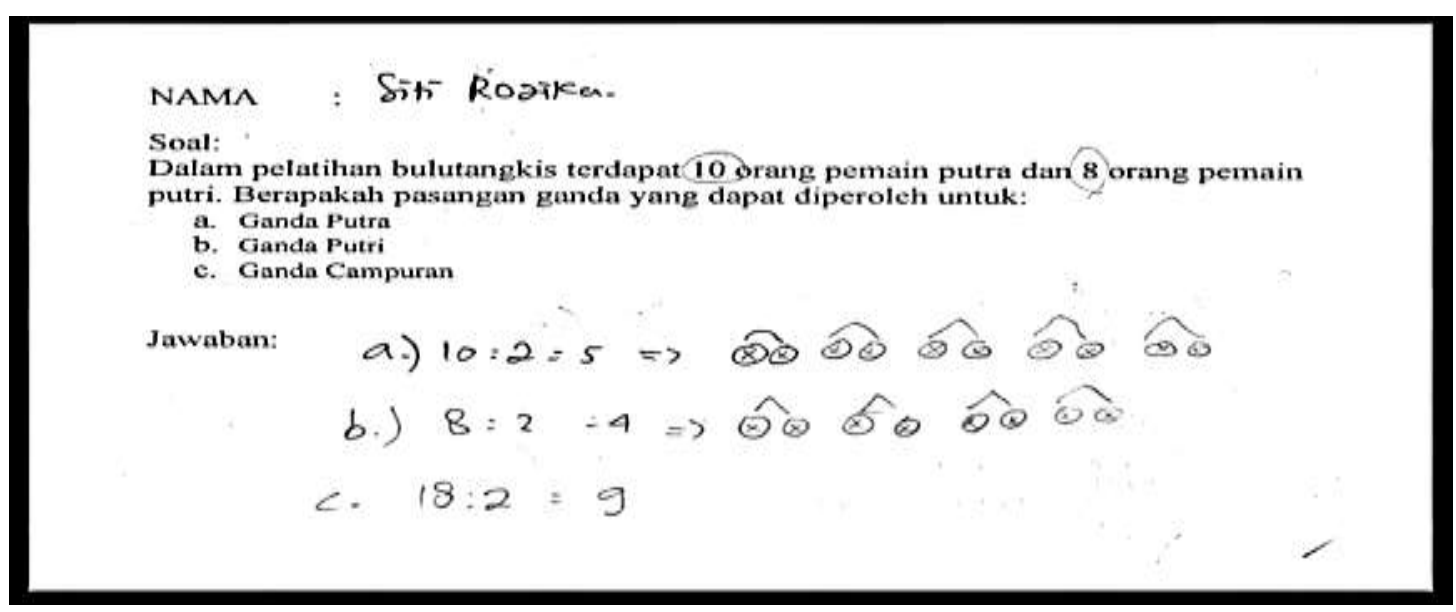

Figure 1. The example of student $A$ answers of question

The question of the above counting rule is the question of finding the number of ways that can be obtained. To be able to answer, students should be able to associate the concept of combination with the above problems. The problem solving of the students tends to use the concept of combination with simple division procedures, resulting in misinterpretation when there are 10 sons and wants to find the number of multiple pairs 
earned. Students use the concept of simple division by dividing the two 10 sons and obtaining the result 5 . While it is known that the problem should be solved by the principle of combination, from $\mathrm{n}$ objects made arrangement of combinations of $\mathrm{k}$ objects with no regard to elements, so there are different arrangements.

The emergence of learning obstacles above is caused by students who still do not understand about the concept of a combination. This leads to a series of didactic situations developed subsequently no longer correspond to the learning trajectory that every student should pass, which students end up experiencing difficulty in learning.

Based on the analysis of preliminary study results as described earlier, it can be concluded that the learning difficulties experienced by students are learning obstacles that are epistemological. Therefore, it is necessary to prepare a learning path that can minimize the difficulties experienced by students. The development of a learning path will have an impact on the achievement of learning objectives. This study aims to determine the difficulties of learning experienced by students and arrange trajectory learning in accordance with the difficulties experienced by students.

\section{Experimental Method}

The approach used in this study is a qualitative approach that emphasizes the character of descriptive studies. In this regard, data collection techniques used in the form of test instrument tests, observations, interviews, and documentation. The data is used to determine the learning obstacles experienced by students and as a reference for the formulation of relevant hypothetical learning trajectory. Subjects in this study were students of class XII senior high school as many as 70 people.

\section{Results and Discussion}

Prior to analysing the characteristics of obstacle learning, a test instrument was prepared to be tested to some students who had received learning material on counting rules. Instrument obstacle learning test is expected to diagnostic learning difficulties experienced by students. Here is an explanation of 2 questions consisting of 8 test questions about learning obstacle.

"Problems 1:

Explain what you know about:

a. The definition of multiplication?

b. The definition and formula of permutation?

c. The definition and formula combinations?

d. Difference between permutation and combination?"

Problem number 1 is a form of a question that is prepared to know the understanding of concepts and procedures in the material rules of counting. On questions $a, b$, and c are asked about the meaning and procedure of the rules of multiplication, permutation, and combination so that students understand the basic concepts in chopping. Students are asked to understand the concept in order to relate mathematical problems to the concept of what they are wearing, so that appropriate procedures can be used to solve mathematical problems. When students have understood from the definition of 
permutations and combinations, on the matter $d$ students are asked to distinguish between the two. This is considered important because when already understood from the understanding of each concept, then the students can also distinguish from each concept terebut.

Most students have problems understanding the rules of multiplication, permutations, combinations, and differences between permutations and combinations contained in question number 1. Looking at the variation of student's answer errors in question number 1, the researcher divides into four parts. First student error in aspect definition of multiplication rules, both students' errors in defining permutations, the three barriers to the combination definition aspect, and the four errors in distinguishing between permutations and combinations.

First discussed about student error in aspect of multiplication rule definition in rule of counting. Most students do not answer the definition of multiplication rules in the counting rule. From the interviews of some students, it is found that students still have difficulty defining the rules of multiplication in the form of words, but students prefer if directly in the application or workmanship. This is because students are only accustomed to working on examples of applications only, but not familiar with defining a material.

Second is in the aspect of the definition of permutation, in this section there are still some students who do not answer about the definition of permutation. As in the case of the first part, the lack of emphasis on learning in terms of the definition of a material. Many students are more concerned with the application of a material, whereas the definition is a foundation for applying the formula of the material. Errors in defining permutations also occur in students. The answer is shown in Figure 2.

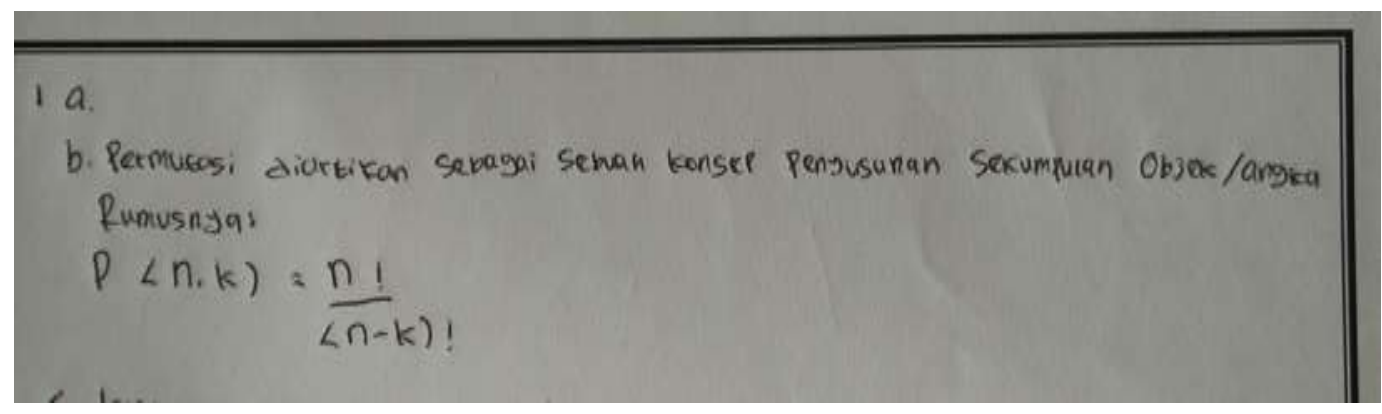

Figure 2. The example of student answers of problems 1

Students only mention that permutation is as a concept of arranging a set of objects / numbers. The student's answer is still less precise, it should be in addition to that already answered by the student and then added with attention to the order ( $\mathrm{BB} \neq \mathrm{BA}$ ).

Third is an obstacle to the combination definition aspect. There are still many students who write the formula of the combination only, but do not write the definition of a combination. This means students do not yet understand the definition of the combination. Another error occurs in some students, ie students have errors defining combinations, some are interchangeable with definitions of permutations that are in the 
following student answers "combinations are part or all of the objects without any repetition".

Fourth is the student's mistake in distinguishing between permutations and combinations. From the error in the previous section it has been seen that most students have not been able to define permutations and combinations. So in terms of differentiating between permutations and combinations there are also many errors. First there are still many students who do not fill in this question, the two students only answer shortly by writing that the permutation is not repeated and the combination can be repeated. This answer is less precise because it can be repeated or can not be repeated what it means. Some students also answer the following "Permutation is something of consecutive data, while the combination is not sequential. It appears that the student only remembers the keywords "in sequence and not in order", but does not understand the meaning of the word. It should be in the permutation pay attention to the sequence $(A B \neq B A)$, while the combination does not pay attention to the sequence $(A B$ $=\mathrm{BA})$.

\section{"Problems 2:}

From city A to town B there are 3 lines. From city B to city $\mathrm{C}$ there are 4 lanes. Determine how many ways you can get from city A to city $\mathrm{C}$ through city B by using:

a. Tree chart;

b. Multiplication rules."

Problem number 2 is a form of problem from a real problem into the form of multiplication rules. Where in question a, students are asked to describe the probability of an answer by using a tree diagram. Then on problem $b$, students are asked to solve the problem into multiplication form. So in the end students can draw conclusions between answers a and answer $b$ is the same way in solving multiplication rules, and students are more understanding about the concept of multiplication rules.

In question number 2 representing the principle of multiplication rule, it is found that about $32.86 \%$ of students are wrong when answer number 2 . Errors are found when the student is wrong in determining the number of elements that will be multiplied, such as the student's answer example in Figure 3.

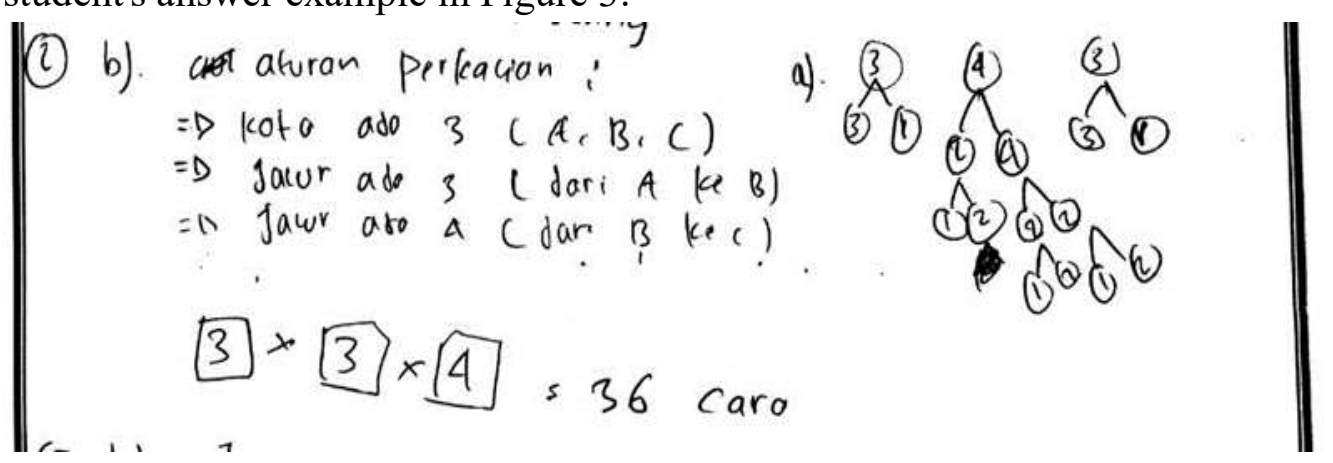

Figure 3. The example of student answers of problems 2

One of the student answers above shows that the number of incident elements is 3 , whereas there are 2 elements of the event that is the first element there are 3 paths and 
the second event element there are 4 paths. Learning obstacle above is in line with the opinion of Brosseau, naturally students have learning difficulties (learning obstacle), some of these difficulties can not be avoided [6]. The author feels the need for analysis and results that can minimize learning difficulties that students experience.

From the findings that have been found, the authors conclude some student difficulties that is (1) Students are difficult in defining rules of multiplication, permutation, and combination using their own language; (2) Students are wrong in applying the rules of multiplication, permutation, and combination in solving real problems; (3) Student is wrong in applying procedure of multiplication, permutation and combination in solving real problem.

Based on the results of obstacle learning findings analysis obtained from the results of diagnostic tests, observations, and interviews researchers concluded several causes, namely (1) Lack of teachers or teaching materials that ask students to define the notion of the rules of multiplication, permutation, and combination; (2) Teachers and teaching materials provide formula of rules of multiplication, permutation, and combination directly and give way of application, students should be invited to find the formula of multiplication, permutation and combination; (3) Lack of teachers and teaching materials in providing mathematical problems that train students in multiplication, permutation and combination rules. Therefore, proper learning trajectory analysis is needed, because according to Clements and Sarama's opinion that learning trajectory describes the learning objectives, the process of thinking and learning of students at different levels, and learning activities involving students [7]. This means that learning trajectory is a sequence or stage of learning activities in conveying the material with respect to different levels of student thinking.

Having found the learning difficulties of students, and then analyzed what are the causes that cause learning obstacle. The authors develop an alternative learning solution in the form of hypothetical learning trajectory that can overcome student learning difficulties. Hypothetical learning trajectory is arranged according to the appropriate material sequence and the real problem that the author deliberately chose to support the achievement of the learning objectives. This is the result of hypothetical learning trajectory that is divided based on several situations made, namely (1) Determining the number of ways of setting objects by using known ways; (2) Create a tree diagram in determining the number of ways of setting objects; (3) Determining the number of ways of setting objects that have large number of objects; (4) Rules of filling place to determine the number of ways to arrange the serial number of goods; (5) Know the factorial form and define it; (6) addition and subtraction in factorial; (7) Multiplication and factorial division; (8) Declare the number form by using factorial notation; (9) Determine the value of $n$ that satisfies the equation of the factorial notation; (10) Create a tree diagram to define permutations; (11) Lowering the permutation formula of different elements in the problem of arranging the ball into the box; (12) Lowering the permutation formula of the same elements in determining the number of objects; (13) Draw a picture illustration and derive a circular permutation formula from the problem 
of the composition of the circle table bench; (14) Define a combination of real problems; (15) Lowered the formula of the combination in the preparation of the ball into the box; (16) Differentiate between permutations and combinations in real problems. The sixteen situations are designed for 4 lesson meetings, and at the end of each learning the student is asked to describe what he or she has learned.

Hypothetical learning trajectory that has been prepared is expected to minimize student learning difficulties. Because according to Simon, hypothetical learning trajectory is a learning plan in the form of prediction or prediction to overcome problems that may arise in learning activities [8]. Problems that occur at the time of learning have been predicted and have alternative solutions through hypothetical learning trajectory that has been prepared.

\section{Conclussion}

Based on the result, the ability of XII high school students in solving the problem of counting rules is still low. Most students experience learning obstacle. Students are accustomed to using the formula given by the teacher, but not yet understand the concepts, principles, and procedures of the counting rules as a whole. The learning materials of the counting rules presented in the textbooks do not construct students' understanding, so they are not Support meaningful learning. Hypothetical learning trajectory based on the obstacle learning analysis experienced by students and the analysis of the causes of difficulty can occur. Preparation of hypothetical learning trajectory through the learning situations that have been designed is expected to form problem-solving skills for students, so that the reconstruction process in understanding the concepts, principles, and procedures of counting can occur. Through the reconstruction process, students are formed to be more independent so that they are not dependent on the ready-to-eat formula.

\section{References}

[1] Sanjaya W 2010 Strategi pembelajaran berorientasi standar proses pendidikan (Jakarta: Kencana Prenada Group)

[2] Redja, M 2012 Pengantar pendidikan (Jakarta: PT Grafindo Persada)

[3] Rahmawati 2016 Hasil TIMSS 2015: Diagnosa hasil untuk perbaikan mutu dan peningkatan capaian (Jakarta: Kemendikbud)

[4] Setiadi 2012 Kemampuan matematika siswa SMP Indonesia: Menurut benchmark internasional TIMSS 2011 (Jakarta: Kemendikbud)

[5] Didi S 2010 Metapedadidaktik dan Didactical Design Research (DDR): Sintesis hasil pemikiran berdasarkan lesson study (Bandung: FPMIPA UPI)

[6] Brosseau G 2002 Theory of didactical situation in mathematics (Dordrecht: Kluwer Academic Publishers)

[7] Clements and Sarama 2009 Learning Trajectories in Early MathematicsSequences of Acquisition and Teaching (Canada: Canadian Language \& 


\section{Research Network)}

[8] Simon M A 1995 Developing New Models of Mathematics Teaching: An Imperative for Research on Mathematics Teacher Development in E Fennema \& B S Nelson Mathematics Teachers in Transition (NJ: Lawrence Erlbaum Associates)

\section{Acknowledgments}

We thank students and teacher for their help and participation. 